\title{
SPIF process of axisymmetric parts made of AA1060-H14 aluminum alloy tested on 2 axis-NC lathe machine
}

Ben Said Lotfi ( $\sim$ bensaid_rmq@yahoo.fr)

Ecole Nationale d'Ingenieurs de Sfax https://orcid.org/0000-0001-7652-3068

Abir Bouhamed

Ecole Nationale d'Ingenieurs de Sfax

Mondher Wali

Ecole Nationale d'Ingenieurs de Sfax

Lioua Kolsi

Ecole Nationale d'Ingenieurs de Monastir

Fakhreddine Dammak

Ecole Nationale d'Ingenieurs de Sfax

Original Article

Keywords: SPIF-T operation, NC turning machine, NC milling machine, forming

Posted Date: July 22nd, 2020

DOI: https://doi.org/10.21203/rs.3.rs-21529/v2

License: (c) (1) This work is licensed under a Creative Commons Attribution 4.0 International License. Read Full License 
The authors have withdrawn this preprint from Research Square 